\title{
Article
}

\section{Influence of Nucleation Seeding on the Hydration Mechanisms of Tricalcium Silicate and Cement}

\author{
Jeffrey J. Thomas, Hamlin M. Jennings, and Jeffrey J. Chen
}

J. Phys. Chem. C, 2009, 113 (11), 4327-4334• DOI: 10.1021/jp809811w • Publication Date (Web): 19 February 2009

Downloaded from http://pubs.acs.org on April 28, 2009

\section{More About This Article}

Additional resources and features associated with this article are available within the HTML version:

- $\quad$ Supporting Information

- $\quad$ Access to high resolution figures

- $\quad$ Links to articles and content related to this article

- Copyright permission to reproduce figures and/or text from this article

\section{View the Full Text HTML}




\title{
Influence of Nucleation Seeding on the Hydration Mechanisms of Tricalcium Silicate and Cement
}

\author{
Jeffrey J. Thomas, ${ }^{* \dagger}$ Hamlin M. Jennings, ${ }^{\dagger \dagger}$ and Jeffrey J. Chen ${ }^{\S}$ \\ Department of Civil and Environmental Engineering and Department of Materials Science and Engineering, \\ Northwestern University, Evanston, Illinois 60208, and Lafarge Centre de Recherche, \\ 38291 Saint Quentin Fallavier Cedex, France
}

Received: November 6, 2008; Revised Manuscript Received: January 16, 2009

\begin{abstract}
The fundamental chemical hydration process of portland cement and its main mineral component, tricalcium silicate, was studied by investigating the effects of various additives. A relatively small amount (1-4 wt \%) of well-dispersed calcium silicate hydrate $(\mathrm{C}-\mathrm{S}-\mathrm{H})$, a pure form of the main hydration product, significantly increases both the early hydration rate and the total amount of hydration during the early nucleation and growth period (the first $\sim 24 \mathrm{~h}$ ), as measured by calorimetry. This is attributed to a seeding effect whereby the $\mathrm{C}-\mathrm{S}-\mathrm{H}$ additive provides new nucleation sites within the pore space away from the particle surfaces. This mechanism is verified by a digital simulation of the hydration process that reproduces key features of the hydration kinetics. The results provide strong evidence that the hydration process is autocatalytic such that the $\mathrm{C}-\mathrm{S}-\mathrm{H}$ gel product stimulates its own formation. The seeding effect of $\mathrm{C}-\mathrm{S}-\mathrm{H}$ also provides a new explanation of the hydration-accelerating effects of various forms of reactive silica because these additives form $\mathrm{C}-\mathrm{S}-\mathrm{H}$ by reacting with aqueous calcium ions released by cement dissolution. Experiments involving sucrose, a hydration retarder, confirm that sucrose interferes with the normal nucleation process on the particle surface.
\end{abstract}

\section{Introduction}

The most important unresolved issues in the field of cement chemistry center around the specific mechanisms that control the rate of cement hydration and the development of the nanoscale structure of the main hydration product, the calcium silicate hydrate $(\mathrm{C}-\mathrm{S}-\mathrm{H})$ (cement chemistry notation: $\mathrm{C}=\mathrm{CaO}, \mathrm{S}=\mathrm{SiO}_{2}, \mathrm{H}=$ $\mathrm{H}_{2} \mathrm{O}$ ) gel. This is a particularly challenging problem when interpreting the influence of retarders and accelerators, a group of chemicals that strongly influence the early rate of hydration. One of the problems has been that these chemicals invariably add a convoluting counterion or are in themselves complex. Here, the powerful accelerating effects of a well-dispersed form of $\mathrm{C}-\mathrm{S}-\mathrm{H}$ are described for the first time. Because this additive does not affect the solution chemistry, its effects provide direct insights into the fundamental reaction process.

Pure tricalcium silicate $\left(\mathrm{C}_{3} \mathrm{~S}\right)$ powder serves as a model for portland cement both because it is the main constituent (accounting for $50-70 \%$ of the mass of portland cement) and because its reaction kinetics are essentially similar to those of portland cement. The results and analysis in this article will focus on the hydration of pure $\mathrm{C}_{3} \mathrm{~S}$, but the accelerating effects of the seed material and the main conclusions regarding the hydration mechanisms are shown to be valid for portland cement as well.

The hydration of $\mathrm{C}_{3} \mathrm{~S}$ can be written as

$\mathrm{C}_{3} \mathrm{~S}(\mathrm{~s})+(x+1.3) \mathrm{H}_{2} \mathrm{O}(\mathrm{l}) \Longrightarrow \mathrm{C}_{1.7}-\mathrm{S}-\mathrm{H}_{x}(\mathrm{~s})+1.3 \mathrm{Ca}(\mathrm{OH})_{2}(\mathrm{~s})$

\footnotetext{
* Corresponding author. E-mail: jthomas@northwestern.edu.

$\dagger$ Department of Civil and Environmental Engineering, Northwestern University.

$\$$ Department of Materials Science and Engineering, Northwestern University.

$\S$ Lafarge Centre de Recherche.
}

where $x$, the molar water content of $\mathrm{C}-\mathrm{S}-\mathrm{H}$, depends on the precise definition of the solid $\mathrm{C}-\mathrm{S}-\mathrm{H}$ phase. Reaction 1 proceeds by a dissolution-precipitation process, with the ionic concentrations of calcium and silicon in the pore solution remaining roughly constant with time. The $\mathrm{Ca}(\mathrm{OH})_{2}$ phase forms primarily as micrometer-scale crystals whereas the $\mathrm{C}-\mathrm{S}-\mathrm{H}$ gel phase is generally believed to consist of nanometer-scale solid particles that are packed, or agglomerated, into randomly oriented structures. ${ }^{1-4}$ The molar water content of the $\mathrm{C}-\mathrm{S}-\mathrm{H}$ nanoparticles in neat portland cement and $\mathrm{C}_{3} \mathrm{~S}$ pastes, including chemically bound and interlayer water inside the particles but excluding all adsorbed and liquid water, was recently determined to be $x=1.8 .^{5}$ The strong electrostatic bonding between the negatively charged $\mathrm{C}-\mathrm{S}-\mathrm{H}$ particles, which is responsible for the cohesion of hydrated cement, results from an inversion of the effective surface charge in the presence of divalent calcium ions and high $\mathrm{pH}$ in the surrounding solution. ${ }^{6,7}$ The colloidal, or nanogranular, nature of the $\mathrm{C}-\mathrm{S}-\mathrm{H}$ gel has a controlling effect on many of the bulk properties of cement paste and concrete. ${ }^{8-11}$

The kinetics of cement hydration have been measured using a variety of techniques. Quasielastic neutron scattering (QENS), ${ }^{12-19}$ differential scanning calorimetry, ${ }^{20-22}$ and proton NMR relaxation ${ }^{23-26}$ all measure the progressive trapping of water in very fine pores associated with the hydration products, in particular, the nanopores formed between the $\mathrm{C}-\mathrm{S}-\mathrm{H}$ particles. These experiments have provided a significant amount of information about the evolution of the microstructure during hydration. In contrast, isothermal calorimetry measures the net reaction exotherm associated with the hydration reactions. Because the exothermic reaction step is the dissolution of the cement minerals, particularly tricalcium silicate, ${ }^{27}$ isothermal calorimetry effectively measures the rate of cement or $\mathrm{C}_{3} \mathrm{~S}$ consumption rather than the formation of the hydration product. 


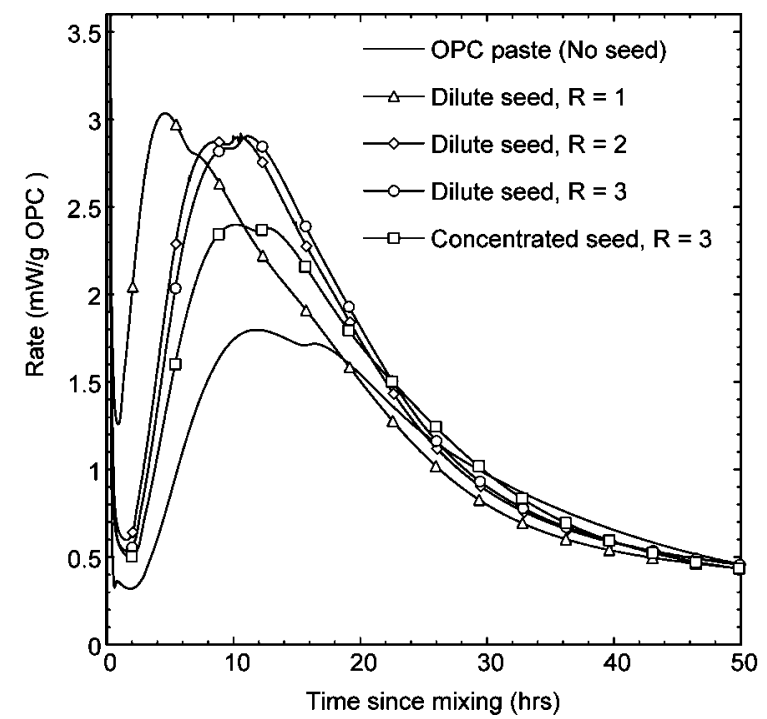

Figure 1. Effect of the $\mathrm{C}-\mathrm{S}-\mathrm{H}$ seed on the early hydration kinetics of portland cement paste. The lines are isothermal calorimetry data, and the symbols identify individual data sets. In each case, the amount of seed added is $2 \%$ mass of solid $\mathrm{C}-\mathrm{S}-\mathrm{H}$ per mass of cement, and the $\mathrm{Ca} / \mathrm{Si}$ of the seed is $1 . R$ is the ratio of $\mathrm{SiO}_{2}$ to $\mathrm{Na}_{2} \mathrm{O}$ in the sodium silicate solution used to make the seed. Dilute seed was made using solutions with a water/solids ratio of 30 and has a solids content of $7 \%$ after rinsing and filtering, whereas concentrated seed was made using solutions with a water/solids ratio of 10 and has a solids content of $14 \%$.

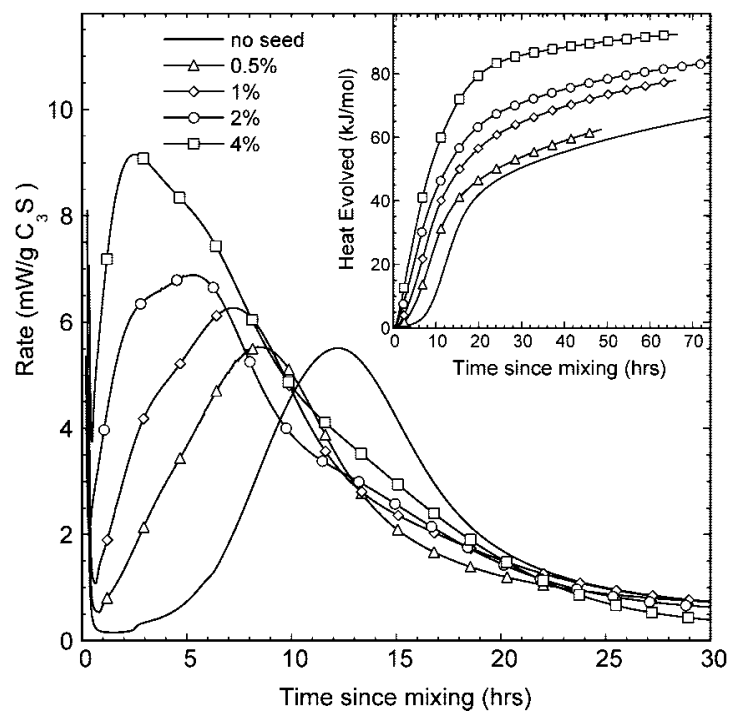

Figure 2. Effect of $\mathrm{C}-\mathrm{S}-\mathrm{H}$ seed made with a molar $\mathrm{Ca} / \mathrm{Si}$ ratio of 1 on the early hydration kinetics of $\mathrm{C}_{3} \mathrm{~S}$ hydration. The seed amounts refer to the mass of solid $\mathrm{C}-\mathrm{S}-\mathrm{H}$ per mass of $\mathrm{C}_{3} \mathrm{~S}$.

Because various additives and changes in curing conditions such as temperature can affect the morphology and pore system of the hydration product, isothermal calorimetry is a more reliable way of measuring the overall kinetics of hydrating cement.

When anhydrous $\mathrm{C}_{3} \mathrm{~S}$ or cement powder is first mixed with water, there is a burst of heat associated with the initial dissolution of the powder lasting for just a few minutes, followed by a period of low heat output lasting for a few hours known as the induction period. During the subsequent $\sim 24 \mathrm{~h}$, the hydration rate accelerates up to a maximum value and then declines, first sharply and then more gradually (Figures 1 and 2).

On the basis of the hydration mechanisms originally proposed by Gartner and Gaidis, ${ }^{28}$ modified by more recent experi- mental $^{29-32}$ and modeling ${ }^{33,34}$ work, a fairly complete hypothesis relating the observed kinetic profile to basic reaction mechanisms has emerged. Shortly after initial mixing, nuclei of the $\mathrm{C}-\mathrm{S}-\mathrm{H}$ gel begin to form at the surface of the $\mathrm{C}_{3} \mathrm{~S}$ particles. The nucleation rate depends primarily on the surface area of the powder, ${ }^{33}$ the calcium concentration in the solution, ${ }^{32}$ and the temperature. Regions of hydration product (consisting of $\mathrm{C}-\mathrm{S}-\mathrm{H}$ nanoparticles, gel pores, and $\mathrm{Ca}(\mathrm{OH})_{2}$ crystals) then begin to grow outward into the pore space and along the $\mathrm{C}_{3} \mathrm{~S}$ surface. The initial period of slow reaction is not a true induction period but occurs simply because the size and number of growing regions are small. As with a standard phase transformation, the reaction rate is proportional to the surface area of contact between the regions of the final phase (hydration product) and the initial phase (solution). This surface area first increases as the size and number of regions increase but then decreases at later times as adjacent regions impinge and grow into each other, resulting in the characteristic rate peak observed by calorimetry. Once the $\mathrm{C}_{3} \mathrm{~S}$ particles become covered with a thick, continuous layer of hydration product, the rate becomes controlled by the rate of diffusion through this layer and decreases slowly for weeks or months.

A complete and accurate description of the early $\mathrm{C}_{3} \mathrm{~S}$ hydration process must account not only for the observed kinetics but also for the nanoparticulate nature of the $\mathrm{C}-\mathrm{S}-\mathrm{H}$ gel. The fact that the hydration kinetics exhibit an extended period with an accelerating hydration rate strongly indicates that the formation of the $\mathrm{C}-\mathrm{S}-\mathrm{H}$ gel is autocatalytic, ${ }^{28}$ implying that existing $\mathrm{C}-\mathrm{S}-\mathrm{H}$ nanoparticles stimulate the formation of new particles. It should be noted that the stimulation of a new $\mathrm{C}-\mathrm{S}-\mathrm{H}$ particle by an existing particle is technically a nucleation process. However, a continuous process of autocatalytic formation of $\mathrm{C}-\mathrm{S}-\mathrm{H}$ particles would have the net effect of causing existing regions of the hydration product to expand outward from the original nucleation site, and thus from the point of view of the macroscopic kinetics, this can be considered growth.

The above hypothesis is compatible both with the observed hydration kinetics and the $\mathrm{C}-\mathrm{S}-\mathrm{H}$ nanostructure. It is also testable in that addition of $\mathrm{C}-\mathrm{S}-\mathrm{H}$ to the paste at the time of mixing should have a significant seeding effect on the hydration kinetics, providing a multitude of additional sites for the nucleation and growth of new regions of hydration product. Seeding with $\mathrm{C}-\mathrm{S}-\mathrm{H}$ should have at least three important effects on the measured hydration kinetics: (1) The induction period should be effectively eliminated because a large number of nuclei are available for growth starting from time zero. (2) The acceleration of the early rate should be greater, and the rate peak should be higher because more regions of hydration product are growing at the same time. (3) The total amount of hydration during the early nucleation and growth period should be greater because the seed material would allow regions of hydration product to nucleate in the pore space between the particles where their growth would not immediately contribute to the process of covering the $\mathrm{C}_{3} \mathrm{~S}$ particles with a layer of hydration product that acts as a diffusion barrier.

An apparent problem with this hypothesis is that previous attempts to seed the hydration of $\mathrm{C}_{3} \mathrm{~S}$ or cement have had mixed results. The addition of ground $\mathrm{C}_{3} \mathrm{~S}$ paste or calcium hydroxide at the time of mixing is ineffective or retarding. ${ }^{35}$ However, a variety of fine powders including silica fume are known to have modest accelerating effects, as is discussed in a later section. Without giving many experimental details, Gartner et al. ${ }^{36}$ show calorimetry data suggesting that the addition of laboratory- 
prepared $\mathrm{C}-\mathrm{S}-\mathrm{H}$ shortens the induction period in $\mathrm{C}_{3} \mathrm{~S}$. However, the plots give little or no indication of a greater maximum rate or an increase in the amount of early hydration (points 2 and 3 above). Therefore, it was necessary to conduct new experiments. Here we report that relatively small additions of $\mathrm{C}-\mathrm{S}-\mathrm{H}$ formed by precipitation from dilute solutions significantly accelerate the hydration of $\mathrm{C}_{3} \mathrm{~S}$ and cement paste on the basis of all three criteria listed above. The results strongly support the autocatalytic theory of $\mathrm{C}_{3} \mathrm{~S}$ hydration, and they provide new details and constraints on the chemistry of hydration. The results presented in this article also provide a more complete explanation of the known accelerating effects of silica fume and other pozzolans on the early hydration rate and shed light on the mechanism by which sucrose retards the hydration process.

\section{Experimental Section}

The $\mathrm{C}-\mathrm{S}-\mathrm{H}$ seed material was prepared by precipitation from aqueous solutions of sodium silicate and calcium nitrate. Sodium silicate solutions were made using either reagent-grade $\mathrm{Na}_{2} \mathrm{SiO}_{3} \cdot 5 \mathrm{H}_{2} \mathrm{O}$ powder or a commercial liquid sodium silicate with a $\mathrm{SiO}_{2} / \mathrm{Na}_{2} \mathrm{O}$ molar ratio of 3.34 (PQ corporation, type "O"). In the latter case, the $\mathrm{SiO}_{2} / \mathrm{Na}_{2} \mathrm{O}$ ratio was adjusted in the range of 3.34 to 1.0 by the addition of $\mathrm{NaOH}$. The calcium nitrate solutions were made using reagent-grade $\mathrm{Ca}\left(\mathrm{NO}_{3}\right) \cdot 4 \mathrm{H}_{2} \mathrm{O}$. The two solutions were combined in a single sealed container, causing the immediate precipitation of $\mathrm{C}-\mathrm{S}-\mathrm{H}$. The molar $\mathrm{Ca} /$ $\mathrm{Si}$ ratio was varied in the range of 0.8 to 1.5 , which is the composition range previously shown to give pure $\mathrm{C}-\mathrm{S}-\mathrm{H} .{ }^{37}$ The ratio of water to solid $\mathrm{C}-\mathrm{S}-\mathrm{H}$ in the combined solution was varied in the range of $10-30$.

After the solution was shaken for $15 \mathrm{~min}$, a Buchner funnel was used to filter the $\mathrm{C}-\mathrm{S}-\mathrm{H}$ precipitate while simultaneously rinsing with $\mathrm{CaO}$ solution to remove the sodium and nitrate. The concentration of $\mathrm{CaO}$ in the rinse solution was approximately that in equilibrium with the precipitated $\mathrm{C}-\mathrm{S}-\mathrm{H}$ at its particular $\mathrm{Ca} / \mathrm{Si}^{38}$ to avoid adding or removing calcium from the $\mathrm{C}-\mathrm{S}-\mathrm{H}$. After rinsing, filtering was continued until no more liquid could be removed, resulting in a translucent gel. ICP analysis of the gel showed only trace levels of sodium. The content of solid $\mathrm{C}-\mathrm{S}-\mathrm{H}$ in the precipitate was measured by weighing a portion of the filtered precipitate before and after oven drying at $115{ }^{\circ} \mathrm{C}$. The solid $\mathrm{C}-\mathrm{S}-\mathrm{H}$ content was essentially independent of the $\mathrm{SiO}_{2} / \mathrm{Na}_{2} \mathrm{O}$ ratio of the sodium silicate solution and the $\mathrm{Ca} / \mathrm{Si}$ ratio of the $\mathrm{C}-\mathrm{S}-\mathrm{H}$. However, the water content of the combined solution had a strong effect on the $\mathrm{C}-\mathrm{S}-\mathrm{H}$ solids content. The amount of $\mathrm{C}-\mathrm{S}-\mathrm{H}$ solids in the final filtered precipitate increased from 7 to $14 \%$ as the water/solid mass ratio of the initial solutions decreased from 30 to 10 .

Two lots of pure triclinic $\mathrm{C}_{3} \mathrm{~S}$ powder were supplied by the Lafarge Research Center in Lyon, France. The lots were ground from the same batch of clinker at different times and thus differ only in their particle size distribution. The specific surface areas as measured by small-angle neutron scattering are $0.71 \mathrm{~m}^{2} / \mathrm{g}$ for batch 1 and $0.57 \mathrm{~m}^{2} / \mathrm{g}$ for batch 2 . A commercial type V portland cement (Lafarge) was used. Experiments were also conducted using the following additives: silica fume (Elkem Microsilica grade 920), colloidal silica with a particle size of $40 \mathrm{~nm}$ (Ludox AS-40), and ground quartz (Min-U-Sil ground silica, U.S. Silica). The addition of $\mathrm{C}-\mathrm{S}-\mathrm{H}$ seed is reported on the basis of mass of solid $\mathrm{C}-\mathrm{S}-\mathrm{H} /$ mass of cement or $\mathrm{C}_{3} \mathrm{~S}$. After the desired amount of the rinsed and filtered $\mathrm{C}-\mathrm{S}-\mathrm{H}$ was weighed out, additional deionized water was added to bring the total water/cement mass ratio of the paste to 0.50 . The $\mathrm{C}_{3} \mathrm{~S}$ or cement powder was then added, and the paste was mixed thoroughly by hand for $2 \mathrm{~min}$.

To measure the hydration kinetics, about $1 \mathrm{~g}$ of paste was tightly sealed inside a $1.3 \mathrm{~mL}$ glass ampule immediately after mixing and then placed into an isothermal calorimeter (model 4200, Calorimetry Sciences Corporation, Linden, UT). This instrument has a sensitivity of $0.4 \mu \mathrm{J}$ and a baseline stability of $\pm 0.08 \mu \mathrm{W} / \mathrm{h}$. All runs were conducted at $20{ }^{\circ} \mathrm{C}$ with a time resolution of $1 \mathrm{~min}$. Samples were placed into the calorimeter about 5 min after the initial contact of solids and water, and another $10 \mathrm{~min}$ was required for the sample temperature to become completely equilibrated to the instrument. Thus, the very exothermic early rapid dissolution of $\mathrm{C}_{3} \mathrm{~S}$ was not accurately captured. The specific surface areas of some pastes made with $\mathrm{C}-\mathrm{S}-\mathrm{H}$ seed were measured in the saturated state using smallangle neutron scattering. Details of the experimental setup and analysis method are given elsewhere. ${ }^{39}$ Specimens for SEM micrographs were impregnated with epoxy, gently ground, and then polished with progressively finer diamond pastes, terminating with a fineness of $0.25 \mu \mathrm{m}$. After being sputter-coated with carbon, they were analyzed in back-scattered electron (BSE) mode in a JEOL 5800 SEM.

\section{Results and Discussion}

Effect of Precipitated $\mathrm{C}-\mathrm{S}-\mathrm{H}$ on the Hydration Kinetics. Figure 1 shows the isothermal calorimetry data for portland cement paste hydrated with $\mathrm{C}-\mathrm{S}-\mathrm{H}$ seed prepared under different conditions. The addition of the seed has a significant accelerating effect, providing support for the mechanism of $\mathrm{C}_{3} \mathrm{~S}$ hydration discussed in the Introduction. The accelerating effect is greater when the seed is precipitated from more dilute solutions (water/solids $=30$ ). This can be attributed to a more open structure that provides more nucleation sites, as evidenced by a greater amount of water trapped within the filtered $\mathrm{C}-\mathrm{S}-\mathrm{H}$. The accelerating effect was also greater when the ratio of $\mathrm{SiO}_{2}$ to $\mathrm{Na}_{2} \mathrm{O}, R$, in the solution used to make the seed was low, despite the fact that the sodium was removed from the seed by rinsing during the filtering step.

Figure 2 shows the isothermal calorimetry data for $\mathrm{C}_{3} \mathrm{~S}$ paste seeded with varying amounts of $\mathrm{C}-\mathrm{S}-\mathrm{H}$ made with $\mathrm{Ca} / \mathrm{Si}=$ 1. For all $\mathrm{C}-\mathrm{S}-\mathrm{H}$ amounts added, the induction period is effectively eliminated. As the amount of $\mathrm{C}-\mathrm{S}-\mathrm{H}$ seed increases, the maximum hydration rate increases whereas the time to reach the rate peak decreases. The total heat evolved at the end of the main hydration period (inset to Figure 2), which is a measure of the amount of hydration that occurs during this time, also increases with the amount of $\mathrm{C}-\mathrm{S}-\mathrm{H}$ added. To test the effect of the $\mathrm{C}-\mathrm{S}-\mathrm{H}$ seed composition on its ability to accelerate hydration, batches were prepared at molar $\mathrm{Ca} / \mathrm{Si}$ ratios of 0.6, 0.83, and 1.2. Differences in the accelerating effect at a fixed additive level of $2 \% \mathrm{C}-\mathrm{S}-\mathrm{H}$ by mass of $\mathrm{C}_{3} \mathrm{~S}$ (not shown) were minor and did not exceed the variation observed between different batches of seed made with the same $\mathrm{Ca} / \mathrm{Si}$.

The degree of hydration, $\alpha$, of $\mathrm{a}_{3} \mathrm{~S}$ paste can be determined by dividing the total amount of evolved heat at a given time by the enthalpy of reaction. Using a value ${ }^{36}$ of $\Delta_{\mathrm{r}} H=-121 \mathrm{~kJ}$ $\mathrm{mol}^{-1}$, the estimated degrees of hydration of the $\mathrm{C}_{3} \mathrm{~S}$ pastes after $24 \mathrm{~h}$ of hydration (a time when the main hydration peak is finished in all pastes) are listed in Table 1. The additional hydration generated by the $\mathrm{C}-\mathrm{S}-\mathrm{H}$ seed during the early hydration period is roughly proportional to the amount that is added.

The early nucleation and growth period that generates the main rate peak ends when a continuous layer of hydration 
TABLE 1: Effect of C-S-H Seed on $\mathrm{C}_{3} S$ Paste ${ }^{a}$

\begin{tabular}{cccc}
\hline $\begin{array}{c}\text { seed } \\
\text { added }(\%)\end{array}$ & $\begin{array}{c}\text { heat }(24 \mathrm{~h}) \\
\left(\mathrm{kJ} \mathrm{mol}^{-1}\right)\end{array}$ & $\alpha(24 \mathrm{~h})$ & $\begin{array}{c}\mathrm{SSA}(28 \mathrm{~d}) \\
\left(\mathrm{m}^{2} / \mathrm{cm}^{3}\right)\end{array}$ \\
\hline 0 & 46.3 & 0.383 & 118 \\
0.5 & 50.0 & 0.413 & \\
1 & 60.7 & 0.502 & 126 \\
2 & 67.3 & 0.556 & 136 \\
2.7 & 72.5 & 0.599 & \\
4 & 83.2 & 0.688 & 147
\end{tabular}

${ }^{a}$ See also Figure 2. Listed are the heat evolved and degree of hydration $(\alpha)$ after $24 \mathrm{~h}$ and the specific surface area (SSA) after $28 \mathrm{~d}$.

product forms around the $\mathrm{C}_{3} \mathrm{~S}$ particles with a thickness sufficient to make the diffusion of ions through it ratecontrolling. The degree of hydration at this point depends on the surface area of the starting powder and on the relative rates of nucleation and product growth. ${ }^{33}$ The nucleation rate and the growth rate are both thermally activated, with activation energies that are similar in magnitude. ${ }^{33}$ Thus, hydrating the same $\mathrm{C}_{3} \mathrm{~S}$ powder at different fixed temperatures within the range of about $10-40{ }^{\circ} \mathrm{C}$ results in significant changes to both the height and time of the main rate peak but has relatively little effect on the total amount of early hydration. ${ }^{33}$

It is hypothesized here that the $\mathrm{C}-\mathrm{S}-\mathrm{H}$ seed increases the amount of early hydration by causing product to form in the capillary pore space away from the $\mathrm{C}_{3} \mathrm{~S}$ surfaces, where it does not interfere with the dissolution of $\mathrm{C}_{3} \mathrm{~S}$. A similar hypothesis was proposed to explain variations in the degree of hydration and compressive strength of pastes made with mixtures of $\mathrm{C}_{3} \mathrm{~S}$ and $\mathrm{C}_{2} \mathrm{~S}^{40}$ In the present case, two separate nucleation and growth processes occur simultaneously: the natural process initiated at the particle surfaces and the seeded process initiated in the pore space. This is illustrated schematically in Figure 3. Evidence for these two processes can be seen in the rate curves in Figure 2 in the form of an additional peak or shoulder that occurs before the main peak and increases in intensity as the amount of $\mathrm{C}-\mathrm{S}-\mathrm{H}$ seed added to the paste increases. A simulation of this effect using a digital hydration model is discussed in the next section. The nucleation of hydration product in the pore space has a permanent effect on the microstructure of the paste. SEM micrographs of mature hydrated paste made with and without $\mathrm{C}-\mathrm{S}-\mathrm{H}$ seed (Figure 4) clearly show that the seeded paste has a more uniform distribution of $\mathrm{C}-\mathrm{S}-\mathrm{H}$ hydration product throughout the pore space and much less capillary porosity. In addition, the specific surface area of mature hydrated $\mathrm{C}_{3} \mathrm{~S}$ paste, which is related to the amount of $\mathrm{C}-\mathrm{S}-\mathrm{H}$ hydration product in the pore space, increases with the amount of seed added (Table 1).

Digital Simulation of the Hydration Process. To test the hypothesis that the double peak or shoulder observed in the calorimetry rate data for seeded pastes is caused by two separate nucleation and growth processes, a simple digital computer model of the hydration process was developed. Within a $3 \mathrm{D}$ cubic array representing a volume of hydrating paste, a fixed number of planes oriented perpendicular to each of the three coordinate directions are selected at random locations, effectively dividing the cubic space into randomly sized rectangular prisms. The planes represent the surfaces of the cement or $\mathrm{C}_{3} \mathrm{~S}$ particles whereas the prismatic spaces between the planes represent the water-filled pore space into which the hydration product grows.

To simulate the natural nucleation and growth process that occurs in an unseeded $\mathrm{C}_{3} \mathrm{~S}$ or cement paste, nuclei of the
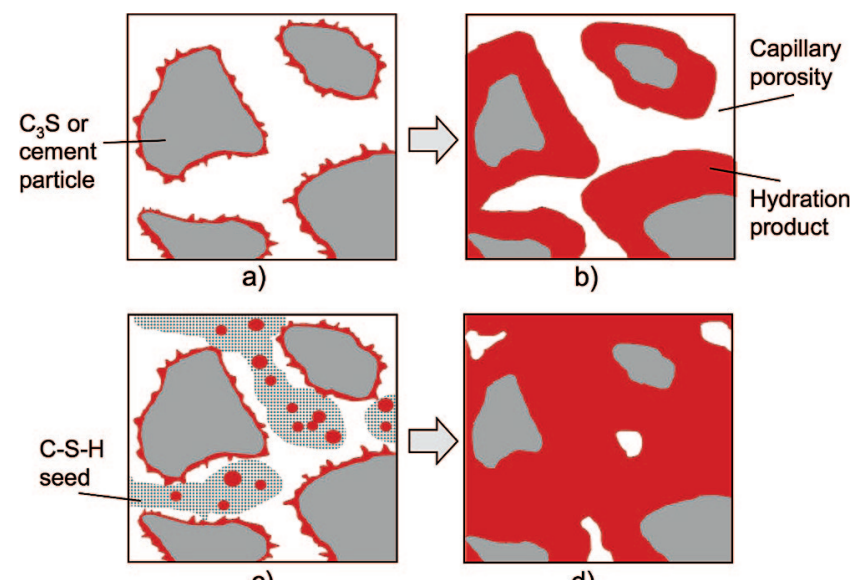

c)

d)

Figure 3. Schematic of the hydration process. (a) Normal unseeded paste a few minutes after mixing. The hydration product (primarily the $\mathrm{C}-\mathrm{S}-\mathrm{H}$ gel) nucleates on particle surfaces and begins to grow out into the pore space. (b) After several hours, further nucleation and growth is limited by the thickness of the product layer, leaving significant capillary porosity. (c) Paste with $\mathrm{C}-\mathrm{S}-\mathrm{H}$ seed a few minutes after mixing. The space between the seed regions and cement particles corresponds to parameter $D$ in the digital simulations (discussed in the next section). The hydration product nucleates both on the particle surfaces and within the regions of $\mathrm{C}-\mathrm{S}-\mathrm{H}$ seed, increasing the rate of early hydration. For these two processes, the impingement of adjacent product regions occurs with different kinetics, resulting in a double peak in the overall hydration rate data (Figure 2). (d) After several hours, the overall extent of early hydration is greater, and there is much less capillary porosity (Figure 4).

hydration product are allowed to form only on the internal planes. The nucleation rate, normalized to the remaining planar area that has not transformed to hydration product, is kept constant. Thus, as hydration proceeds and the planes convert to product, the absolute nucleation rate decreases to zero. During each iteration of the program, new nuclei are first formed, and then each existing region of product grows by one pixel in each direction. Growth is simulated simply by changing the pixel values from 0 to 1 . When adjacent regions impinge, no growth occurs. As described to this point, this model simulates the mathematical boundary nucleation and growth model that was first derived ${ }^{41}$ to describe a solid-state transformation nucleated on grain boundaries and that was recently modified ${ }^{33}$ to provide a good physical description of the early hydration period of $\mathrm{C}_{3} \mathrm{~S}$ paste as measured by isothermal calorimetry ${ }^{33}$ and by QENS. ${ }^{42}$

To simulate the additional nucleation and growth caused by the presence of the $\mathrm{C}-\mathrm{S}-\mathrm{H}$ seed, nucleation sites are added at randomly selected locations within the interior of the prismatic regions separating the planes. These seed nuclei grow at the same rate as the natural nuclei that form on the planes, starting from the first iteration. For the simulations presented here, the following parameters were held fixed: the cubic array representing the paste volume is 500 pixels on a side, the number of internal planes in each direction is 3 (dividing the volume into 27 rectangular prisms), and the growth rate is 1 pixel/iteration. To simulate the results shown in Figure 2, the kinetic data for the unseeded $\mathrm{C}_{3} \mathrm{~S}$ paste was first fit using the boundary nucleation and growth model to obtain an appropriate value for the natural nucleation rate (Figure 5, top). The resulting value of $8.7 \times 10^{-5}$ new sites per square pixel of untransformed planar area per iteration was then used for all simulations of the seeded pastes.

The results of the seed simulations are shown in Figure 5, bottom. Parameter $N$ is the number of seed nuclei that are added to the array, and parameter $D$ is the minimum distance 


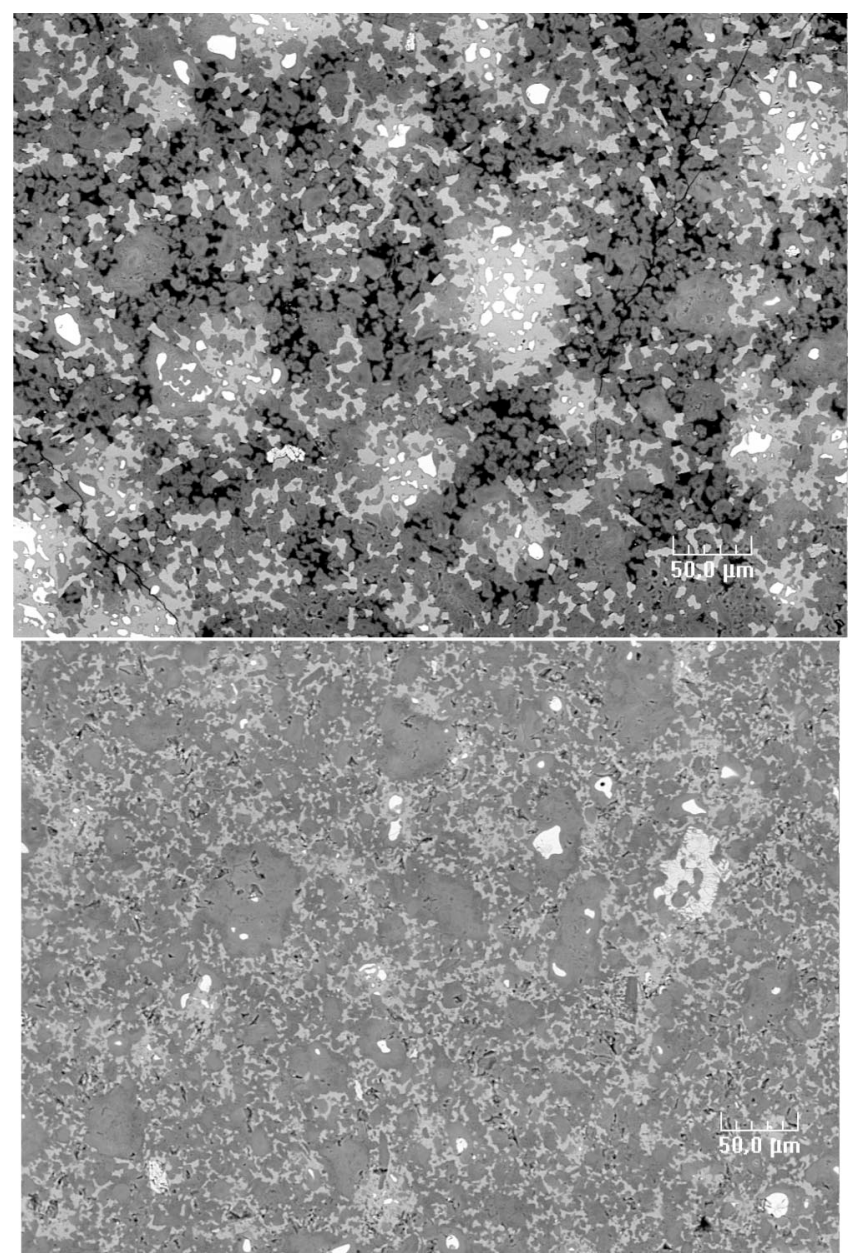

Figure 4. SEM micrographs of hydrated $\mathrm{C}_{3} \mathrm{~S}$ paste made without $\mathrm{C}-\mathrm{S}-\mathrm{H}$ seed (top) and with $2 \% \mathrm{C}-\mathrm{S}-\mathrm{H}$ seed by mass of $\mathrm{C}_{3} \mathrm{~S}$ (bottom). Both pastes were made at a water/solids mass ratio of 0.5 and were 28 days old.

maintained between the internal planes and the seed nuclei. A nonzero value of $D$ was required to form a double peak. For these simulations, the values of $N$ and $D$ were first varied to obtain a qualitative match to the data for $4 \% \mathrm{C}-\mathrm{S}-\mathrm{H}$ seed shown in Figure 2. The resulting value of $N$ (11 000) was then reduced proportionally to represent the pastes with 2 and $1 \%$ seed. Parameter $D$ was found to increase with decreasing seed content. This simple simulation captures the development of an initial peak or shoulder that increases in magnitude as the addition of $\mathrm{C}-\mathrm{S}-\mathrm{H}$ seed increases, as well as the greater overall amount of hydration that occurs during the early hydration period.

Effects of Silica-Containing Additives on the Kinetics. Figure 6 shows the effect of silica fume on the early hydration kinetics of $\mathrm{C}_{3} \mathrm{~S}$. The height of the early rate peak and the amount of early hydration of $\mathrm{C}_{3} \mathrm{~S}$ (Table 2) are increased, but the time required to reach the maximum rate is almost unaffected. This is in good agreement with previous results for silica fume, ${ }^{43-45}$ and similar increases in the amount of early hydration have been observed for a variety of other pozzolans. ${ }^{45,46}$ Secondary pozzolanic reactions, whereby $\mathrm{C}-\mathrm{S}-\mathrm{H}$ gel is formed by reaction between a silica-containing additive and the $\mathrm{Ca}(\mathrm{OH})_{2}$ hydration product, have low net heats of reaction and thus have little direct effect on the measured heat output. The observed accelerating effect has most often been attributed to additional nucleation of the hydration product stimulated by the surface of the silica additive. ${ }^{44,46,47}$ In view of the significant accelerating effect of
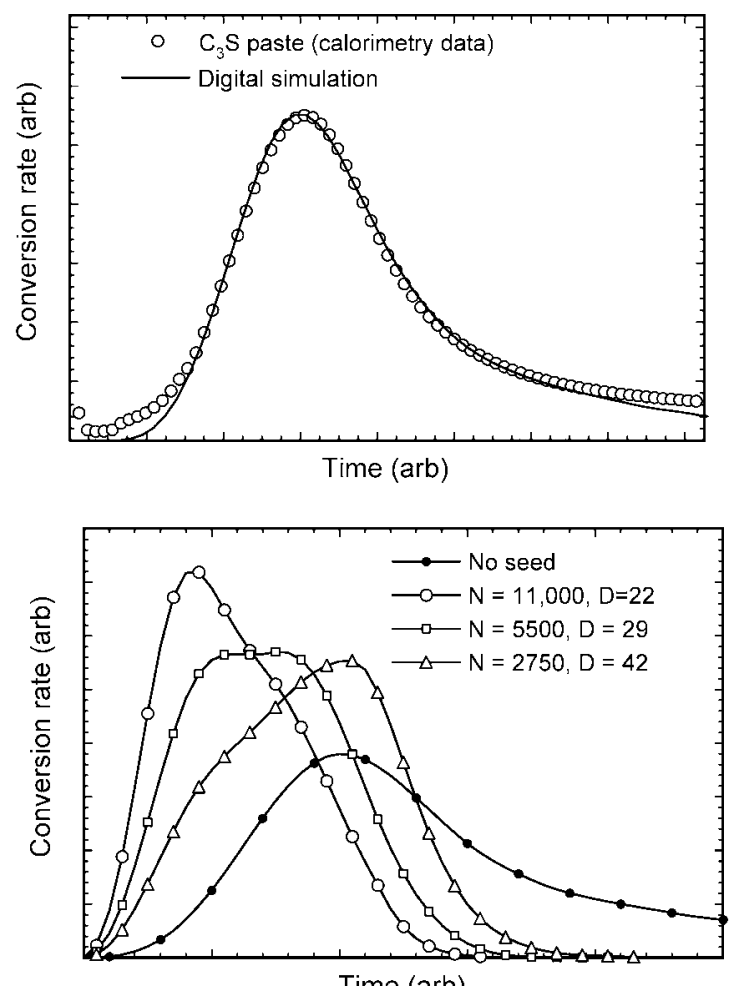

Figure 5. Digital simulation of the early hydration process. (See the text for details.) (Top) Fit (solid line) to the calorimetry data for pure $\mathrm{C}_{3} \mathrm{~S}$ paste, used to establish the nucleation rate on the internal planes representing the $\mathrm{C}_{3} \mathrm{~S}$ particles. (Bottom) Simulation of seeded pastes obtained by adding seed nuclei to the prismatic spaces between the planes. Comparison with Figure 2 shows that the main features of the kinetic data are captured by the simulation.

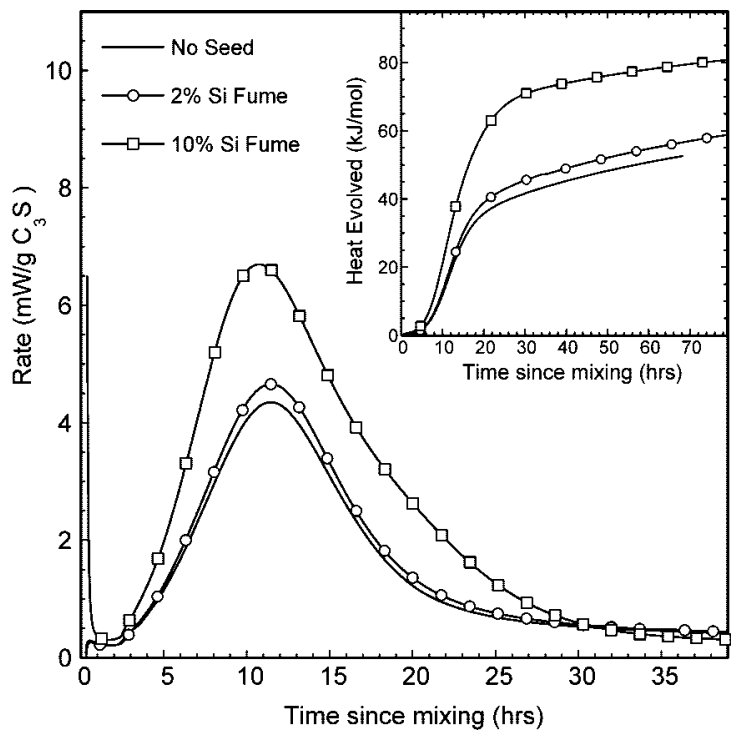

Figure 6. Effect of silica fume on the hydration kinetics of $\mathrm{C}_{3} \mathrm{~S}$. The maximum rate is increased, but the time required to reach the peak is almost unaffected.

$\mathrm{C}-\mathrm{S}-\mathrm{H}$ reported here, we hypothesize that the nucleating agent is not the silica surface itself but rather the pozzolanic $\mathrm{C}-\mathrm{S}-\mathrm{H}$ that forms near this surface. Because the pozzolanic reaction with silica fume is relatively slow, additional nucleation sites are added gradually over the course of the early hydration period rather than all at once at the time of mixing. Thus, the effect on the kinetics is not as dramatic as when $\mathrm{C}-\mathrm{S}-\mathrm{H}$ is added.

According to this hypothesis, a more soluble source of silica should make a more effective accelerator because it would react 
TABLE 2: Degree of Hydration $(\alpha)$ of $\mathrm{C}_{3} \mathrm{~S}$ Pastes after 24 and $40 \mathrm{~h}$ of Hydration as a Function of the Amounts of Silica Fume and Ludox Colloidal Silica

\begin{tabular}{lcc}
\hline \multicolumn{1}{c}{ additive } & heat $(24 \mathrm{~h})(\mathrm{kJ} / \mathrm{mol})$ & $\alpha(24 \mathrm{~h})$ \\
\hline no additive & 38.7 & 0.320 \\
$2 \%$ Si fume & 42.3 & 0.349 \\
$10 \%$ Si fume & 66.3 & 0.548 \\
$2 \%$ Ludox & 40.9 & 0.338 \\
$4 \%$ Ludox & 46.1 & 0.381 \\
$10 \%$ Ludox & 54.2 & 0.448
\end{tabular}

to form $\mathrm{C}-\mathrm{S}-\mathrm{H}$ seed more quickly. This is indeed the case: colloidal silica, which is much more reactive than silica fume, provides a stronger accelerating effect, although not as great as that of $\mathrm{C}-\mathrm{S}-\mathrm{H}$ itself (Figure 7). The accelerating effect of colloidal silica was first reported by Stein and Stevels. ${ }^{48}$ It can be seen from Figure 7 that the induction period is still present when colloidal silica is added. This supports the present hypothesis that the primary nucleating agent is $\mathrm{C}-\mathrm{S}-\mathrm{H}$ because a source of pure silica, no matter how reactive, must still depend on the release of calcium from $\mathrm{C}_{3} \mathrm{~S}$ dissolution to form $\mathrm{C}-\mathrm{S}-\mathrm{H}$ seed.

Comparing the insets to Figures 2 and 7 and the values in Tables 1 and 2, it can be seen that colloidal silica does not increase the amount of hydration during the early hydration period as much as does the $\mathrm{C}-\mathrm{S}-\mathrm{H}$ seed, and the rate curves do not exhibit a secondary peak. On the basis of the hypothesis outlined in the previous sections and the simulation results, this indicates that colloidal silica is less effective than $\mathrm{C}-\mathrm{S}-\mathrm{H}$ at stimulating product formation in the pore space away from the $\mathrm{C}_{3} \mathrm{~S}$ surfaces. The requirement that colloidal silica react with calcium released by $\mathrm{C}_{3} \mathrm{~S}$ dissolution to form $\mathrm{C}-\mathrm{S}-\mathrm{H}$ may result in preferential seed formation close to the $\mathrm{C}_{3} \mathrm{~S}$ surfaces. An additional test was conducted using a $10 \%$ addition of finely ground crystalline silica (silica flour). In this case, the heat release was identical to the $\mathrm{C}_{3} \mathrm{~S}$ control (Figure 7). This establishes that the presence of silica in the paste is not sufficient to stimulate the formation of the hydration product if it is not reactive.

The proposed mechanism of acceleration by pozzolanic $\mathrm{C}-\mathrm{S}-\mathrm{H}$ is also in agreement with the results of Ogawa et al., ${ }^{46}$

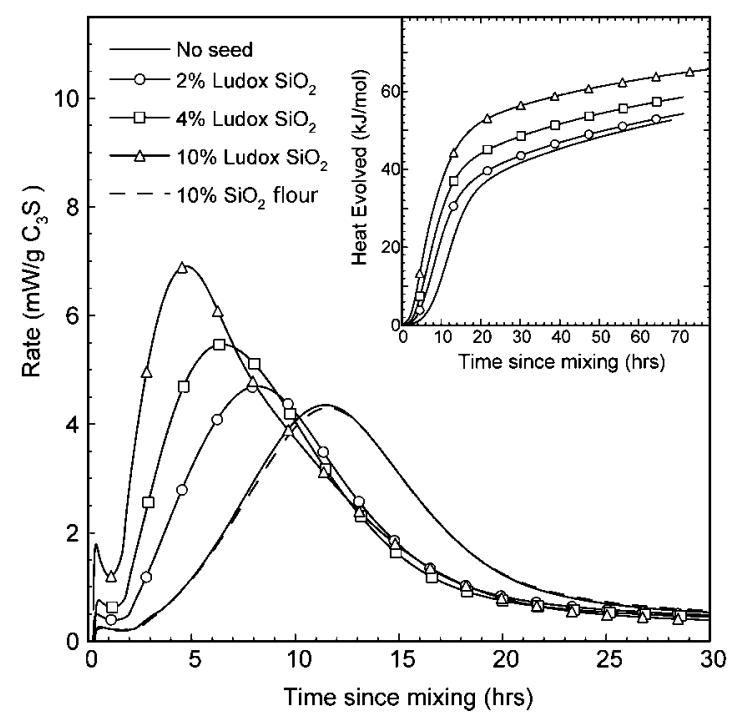

Figure 7. Effect of Ludox colloidal silica and silica flour (dashed line) on the hydration kinetics of $\mathrm{C}_{3} \mathrm{~S}$. For the very soluble colloidal silica, the accelerating effect is significant, whereas for the chemically inert ground quartz there is no effect.

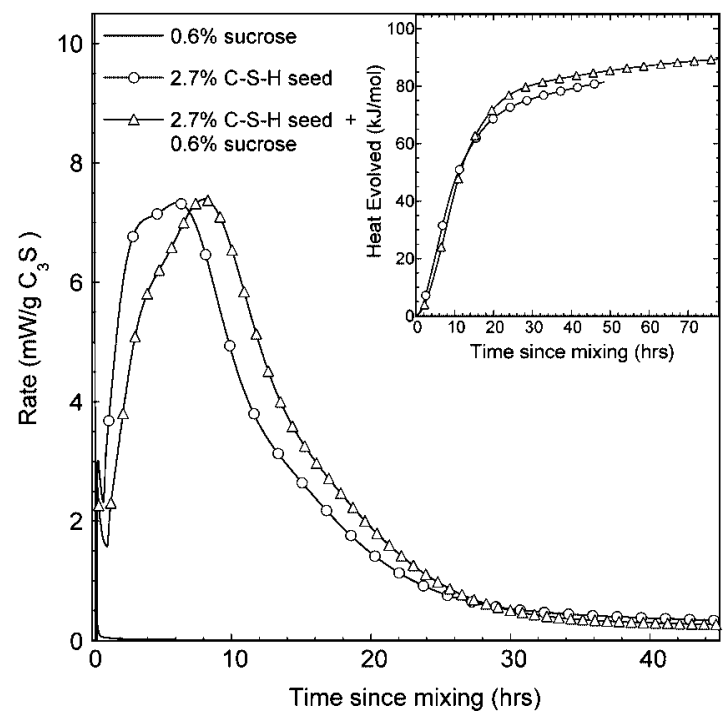

Figure 8. Combined effect of $2.71 \% \mathrm{C}-\mathrm{S}-\mathrm{H}$ seed and $0.6 \%$ sucrose, both added at the time of mixing. When only $0.6 \%$ sucrose was added, the system was completely retarded (no hydration peak) for at least $336 \mathrm{~h}$ (this data is plotted but lies close to the time axis).

who studied the effects of five natural and man-made pozzolanic materials on the hydration of $\mathrm{C}_{3} \mathrm{~S}$. The amount of early $\mathrm{C}_{3} \mathrm{~S}$ hydration measured by calorimetry was increased by each pozzolan. However, the time of the main rate peak varied significantly, with more reactive pozzolans giving an earlier peak. It should be noted that other finely divided materials, such as calcium carbonate, appear to increase the early hydration rate of $\mathrm{C}_{3} \mathrm{~S}^{49}$ modestly even though they do not react to form $\mathrm{C}-\mathrm{S}-\mathrm{H}$. Thus, $\mathrm{C}-\mathrm{S}-\mathrm{H}$ may not be the only nucleating agent, although it appears to be the most effective.

Combined Effects of Seeding and Sucrose. Sugars are effective hydration retarders, and the strong retarding effects of sucrose are particularly well known. ${ }^{17,51-54}$ It is generally accepted that sucrose retards by adsorbing onto the cement particles and hydration products, preventing further nucleation and growth. ${ }^{17,35,50}$ Measurements of the solution concentrations of calcium and silicon in sucrose-retarded pastes ${ }^{51,52}$ appear to provide important clues to the retarding mechanism. ${ }^{36}$ At low to moderate sucrose levels, the concentrations fall on the metastable $\mathrm{C}-\mathrm{S}-\mathrm{H}$ solubility curve originally proposed by Jennings. ${ }^{55}$ This suggests that the normal metastable protective layer is able to form but that the subsequent nucleation and growth of stable $\mathrm{C}-\mathrm{S}-\mathrm{H}$ is stifled. At high sucrose levels, the concentration of aqueous silica is significantly elevated, and the $\mathrm{Ca} / \mathrm{Si}$ ratio of the solution approaches 3 after about 2 h. ${ }^{51}$ This value corresponds to congruent dissolution of $\mathrm{C}_{3} \mathrm{~S}$, which is never observed during normal hydration after the first few minutes. This suggests that high sucrose levels prevent the formation of the metastable $\mathrm{C}-\mathrm{S}-\mathrm{H}$ layer that moderates the dissolution of $\mathrm{C}_{3} \mathrm{~S}$. With such large additions of sucrose, retardation may be permanent.

If sucrose retards hydration by preventing the nucleation of product on the $\mathrm{C}_{3} \mathrm{~S}$ (or cement) particles, then this suggests that the addition of nucleation sites in the form of $\mathrm{C}-\mathrm{S}-\mathrm{H}$ seed should reduce or eliminate the retarding effect. Experiments testing this hypothesis were therefore performed. $\mathrm{A} \mathrm{C}_{3} \mathrm{~S}$ paste with 0.6 wt $\%$ sucrose exhibited no main hydration peak and almost no heat release for at least 2 weeks, at which point the experiment was terminated. A paste was then tested with $0.6 \%$ sucrose and $2.7 \% \mathrm{C}-\mathrm{S}-\mathrm{H}$ seed, both added to the mix water prior to mixing with $\mathrm{C}_{3} \mathrm{~S}$. As shown in Figure 8, the sucrose 


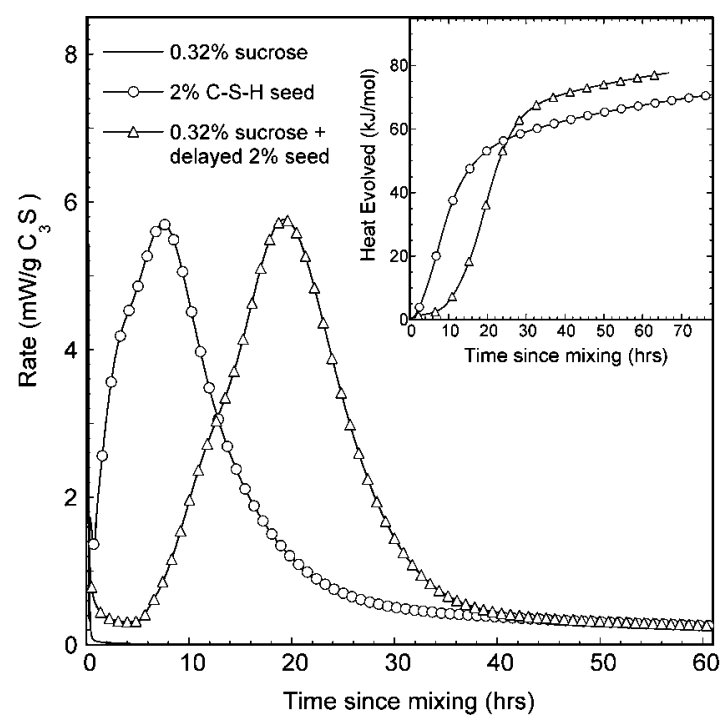

Figure 9. Combined effect of $2 \% \mathrm{C}-\mathrm{S}-\mathrm{H}$ seed and $0.32 \%$ sucrose. The sucrose was added at the time of mixing, and the seed was added 30 min later. When only $0.32 \%$ sucrose was added, the system was completely retarded (no hydration peak) for at least $336 \mathrm{~h}$ (this data is plotted but lies close to the time axis).

has almost no retarding effect when added with the $\mathrm{C}-\mathrm{S}-\mathrm{H}$ seed. It is likely in this case that the sucrose adsorbs completely onto the $\mathrm{C}-\mathrm{S}-\mathrm{H}$ seed, which has a much higher surface area than the $\mathrm{C}_{3} \mathrm{~S}$ particles. The small change in the early peak seen in Figure 8 can be attributed to a fraction of the $\mathrm{C}-\mathrm{S}-\mathrm{H}$ seed being rendered inert by the sucrose.

A more instructive experiment is to allow $\mathrm{C}_{3} \mathrm{~S}$ to react in the presence of sucrose for several minutes to establish the retarding

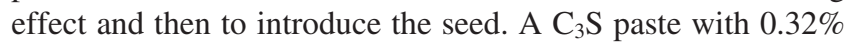
sucrose was completely retarded, with no main hydration peak observed after 2 weeks. Another $\mathrm{C}_{3} \mathrm{~S}$ paste was then mixed with $0.32 \%$ sucrose and allowed to react for $30 \mathrm{~min}$, at which point $2 \% \mathrm{C}-\mathrm{S}-\mathrm{H}$ seed was mixed into the paste and the calorimetry run was started. As shown in Figure 9, the paste with the delayed introduction of $\mathrm{C}-\mathrm{S}-\mathrm{H}$ exhibits a large hydration peak, with the maximum rate moderately delayed from 6 to $20 \mathrm{~h}$. This experiment shows that the retardation mechanism in the presence of sucrose interferes with the formation of new $\mathrm{C}-\mathrm{S}-\mathrm{H}$ gel nuclei on the $\mathrm{C}_{3} \mathrm{~S}$ particle surfaces. The introduction of $\mathrm{C}-\mathrm{S}-\mathrm{H}$ seed into an already-retarded paste provides an alternate hydration pathway that is not affected by the sugar.

It is interesting that the heat evolved by a seeded paste during the early hydration period is slightly greater when it is initially retarded with sucrose (Figure 9, inset). Similarly, sucrose retardation of pure $C_{3} S$ pastes has previously been observed ${ }^{17,54}$ to modestly increase both the maximum rate and the amount of hydration product formed during the nucleation and growth period. This was attributed ${ }^{17}$ to the solubilization of the silicate species by sucrose. Here we suggest that the suppression of nucleation at the $\mathrm{C}_{3} \mathrm{~S}$ surface by sucrose represents an additional mechanism affecting the amount of early hydration.

According to the boundary nucleation model of $\mathrm{C}_{3} \mathrm{~S}$ hydration, ${ }^{33}$ the greater the ratio of the nucleation rate on the $\mathrm{C}_{3} \mathrm{~S}$ particle surface to the product growth rate, the more quickly the particles become fully surrounded by a layer of hydration product, ending the early nucleation and growth period. Thus, factors that increase the nucleation rate more than the growth rate, such as increased temperature ${ }^{33}$ and increased calcium concentration, ${ }^{32}$ decrease the amount of early hydration. Sucrose, by suppressing nucleation on the particle surfaces, would have the opposite effect.

\section{Conclusions}

The addition of relatively small amounts of pure calcium silicate hydrate $(\mathrm{C}-\mathrm{S}-\mathrm{H})$ to portland cement and pure tricalcium silicate $\left(\mathrm{C}_{3} \mathrm{~S}\right)$ pastes causes a significant acceleration of the early hydration kinetics. The induction period, or early slow reaction period, is eliminated, the main hydration rate peak occurs earlier, and the amount of hydration that occurs during the early nucleation and growth period ( $~ 24 \mathrm{~h}$ after mixing) is increased. This is an important finding with possible practical implications for controlling the rate of setting of concrete, but it also sheds light on the complex early hydration process. $\mathrm{C}-\mathrm{S}-\mathrm{H}$ provides nucleation sites for the precipitation of hydration product out of the pore solution; specifically, it seeds the formation of the $\mathrm{C}-\mathrm{S}-\mathrm{H}$ gel, which is the main binding phase in cement paste. This confirms the hypothesis that the formation of $\mathrm{C}-\mathrm{S}-\mathrm{H}$ gel during cement hydration is autocatalytic.

The experiments reported here indicate that the $\mathrm{C}-\mathrm{S}-\mathrm{H}$ seed causes hydration product to form within the pore space between the cement or $\mathrm{C}_{3} \mathrm{~S}$ particles, whereas during normal hydration nucleation occurs only on or near the particle surfaces. The presence of two simultaneous hydration processes in seeded pastes (one initiated at the particle surfaces and one in the pore space) results in the development of a second rate peak or shoulder in the calorimetry data that increases in proportion to the amount of $\mathrm{C}-\mathrm{S}-\mathrm{H}$ seed that is added. This effect was reproduced using a simple digital simulation of the hydration process. The addition of $\mathrm{C}-\mathrm{S}-\mathrm{H}$ seed results in permanent changes to the mature hydrated paste, including a more uniform microstructure with less capillary porosity and a higher specific surface area.

Various types of reactive silica have previously been shown to stimulate the early hydration process. Here we propose that these silica-containing materials first react with calcium ions released by the dissolving cement or $\mathrm{C}_{3} \mathrm{~S}$ to form $\mathrm{C}-\mathrm{S}-\mathrm{H}$, which then in turn seeds the hydration process. This explains why the effectiveness of these additives in stimulating the early hydration rate depends strongly on their solubility, as shown both by experiments presented here and by published work.

Experiments were also conducted using sucrose, a powerful hydration retarder. The retarding effects of sucrose can be negated by adding $\mathrm{C}-\mathrm{S}-\mathrm{H}$ seed at the time of mixing and can be reversed by adding $\mathrm{C}-\mathrm{S}-\mathrm{H}$ later, after the retarding effect has already been established. This confirms that sucrose retards by preventing the nucleation of $\mathrm{C}-\mathrm{S}-\mathrm{H}$ gel on the particle surfaces and that the addition of $\mathrm{C}-\mathrm{S}-\mathrm{H}$ seed provides an alternate pathway for the hydration process.

Acknowledgment. This work was funded by the National Science Foundation under contract CMS 0409571. The smallangle neutron scattering measurements were conducted at the National Center for Neutron Research using facilities supported by the National Science Foundation under Agreement DMR9986442.

\section{References and Notes}

(1) Allen, A. J.; Oberthur, R. C.; Pearson, D.; Schofield, P.; Wilding, C. R. Philos. Mag. B 1987, 56, 263.

(2) Richardson, I. G. Cem. Concr. Res. 1999, 29, 1131.

(3) Gaboriaud, F.; Nonat, A.; Chaumont, D.; Craievich, A. J. Phys. Chem. B 1999, 103, 5775.

(4) Jennings, H. M. Cem. Concr. Res. 2008, 38, 275.

(5) Allen, A. J.; Thomas, J. J.; Jennings, H. M. Nat. Mater. 2007, 6, 311.

(6) Labbez, C.; Jonsson, B.; Pochard, I.; Nonat, A.; Cabane, B. J. Phys. Chem. B 2006, 110, 9219. 
(7) Labbez, C.; Nonat, A.; Jonsson, B.; Pochard, I. J. Colloid Interface Sci. 2007, 309, 303.

(8) Scherer, G. W. Cem. Concr. Res. 1999, 29, 1149.

(9) Thomas, J. J.; Jennings, H. M. Cem. Concr. Res. 2006, 36, 30.

(10) Jennings, H. M.; Thomas, J. J.; Gevrenov, J. S.; Constantinides, G.; Ulm, F.-J. Cem. Concr. Res. 2007, 37, 329.

(11) Constantinides, G.; Ulm, F.-J. J. Mech. Phys. Solids. 2007, 55, 64.

(12) FitzGerald, S. A.; Neumann, D. A.; Rush, J. J.; Bentz, D. P.; Livingston, R. A. Chem. Mater. 1998, 10, 397.

(13) Thomas, J. J.; Neumann, D. A.; FitzGerald, S. A.; Livingston, R. A.

J. Am. Ceram. Soc. 2001, 84, 1811.

(14) Fratini, E.; Chen, S. H.; Baglioni, P.; Bellissent-Funel, M. C. J. Phys. Chem. B 2002, 106, 158.

(15) Allen, A. J.; McLaughlin, J. C.; Neumann, D. A.; Livingston, R. A. J. Mater. Res. 2004, 19, 3242.

(16) Peterson, V. K.; Neumann, D. A.; Livingston, R. A. J. Phys. Chem. B 2005, 109, 14449.

(17) Peterson, V. K.; Juenger, M. C. G. Chem. Mater. 2006, 18, 5798.

(18) Bordallo, H. N.; Aldridge, L. P.; Desmedt, A. J. Phys. Chem. B 2006, 110, 17966.

(19) Fratini, E.; Ridi, F.; Chen, S. H.; Baglioni, P. J. Phys.: Condens. Matter 2006, 18, S2467.

(20) Damasceni, A.; Dei, L.; Fratini, E.; Ridi, F.; Chen, S. H.; Baglioni, P. J. Phys. Chem. B 2002, 106, 11572.

(21) Ridi, F.; Dei, L.; Fratini, E.; Chen, S.-H.; Baglioni, P. J. Phys. Chem. B 2003, 107, 1056.

(22) Ridi, F.; Fratini, E.; Mannelli, F.; Baglioni, P. J. Phys. Chem. B 2005, 109, 14727.

(23) Alesiani, M.; Capuani, S.; Giorgi, R.; Maraviglia, B.; Pirazzoli, I.; Ridi, F.; Baglioni, P. J. Phys. Chem. B 2004, 108, 4869.

(24) Plassais, A.; Pomies, M. P.; Lequeux, N.; Korb, J. P.; Petit, D.; Barberon, F.; Bresson, B. Phys. Rev. E 2005, 72, 041401.

(25) Jaffel, H.; Korb, J. P.; Ndobo-Epoy, J. P.; Morin, V.; Guicquero,

J. P. J. Phys. Chem. B 2006, 110, 7385.

(26) Korb, J. P. Magn. Reson. Imaging 2007, 25, 466.

(27) Grant, S. A.; Boitnott, G. E.; Korhonen, C. J.; Sletten, R. S. Cem. Concr. Res. 2006, 36, 671.

(28) Gartner, E. M.; Gaidis, J. M. Hydration Mechanisms, I. In Materials Science of Concrete; Skalny, J. P., Ed.; The American Ceramic Society: Westerville, OH, 1989.
(29) Damidot, D.; Nonat, A.; Barret, P. J. Am. Ceram. Soc. 1990, 73, 3319.

(30) Thomas, J. J.; Jennings, H. M. Chem. Mater. 1999, 11, 1907.

(31) Garrault-Gauffinet, S.; Nonat, A. J. Cryst. Growth 1999, 200, 565.

(32) Garrault, S.; Nonat, A. Langmuir 2001, 17, 8131.

(33) Thomas, J. J. J. Am. Ceram. Soc. 2007, 90, 3282.

(34) Bullard, J. W. J. Am. Ceram. Soc. 2008, 91, 2088.

(35) Taylor, H. F. W. Cement Chemistry; Thomas Telford: London, 1997.

(36) Gartner, E. M.; Young, J. F.; Damidot, D. A.; Jawed, I. Hydration of Portland Cement. In The Structure and Performance of Cements; Barnes, P.; Bensted, J., Eds.; Spon Press: London, 2002; Chapter 3.

(37) Cong, X.; Kirkpatrick, R. J. J. Am. Ceram. Soc. 1996, 79, 1585.

(38) Chen, J. J.; Thomas, J. J.; Taylor, H. F. W.; Jennings, H. M. Cem.

Concr. Res. 2004, 34, 1499.

(39) Thomas, J. J.; Allen, A. J.; Jennings, H. M. J. Am. Ceram. Soc. 2008, 91, 3362 .

(40) Peterson, V. K.; Neumann, D. A.; Livingston, R. A. J. Mater. Res. 2006, 21, 1836 .

(41) Cahn, J. W. Acta Met. 1956, 4, 449.

(42) Peterson, V. K.; Whitten, A. E. J. Phys. Chem. C, 2009, (in press).

(43) Cheng-Yi, H.; Feldman, R. F. Cem. Concr. Res. 1985, 15, 585.

(44) Larbi, J. A.; Fraay, A. L. A.; Bijen, J. M. Cem. Concr. Res. 1990, 20,506 .

(45) Mostafa, N. Y.; Brown, P. W. Thermochim. Acta 2005, 435, 162.

(46) Ogawa, K.; Uchikawa, H.; Takemoto, K. Cem. Concr. Res. 1980, 10,683 .

(47) Zelic, J.; Rusic, D.; Veza, D.; Krstulovic, R. Cem. Concr. Res. 2000, 30,1655 .

(48) Stein, H. N.; Stevels, J. M. J. Appl. Chem. 1964, 14, 338.

(49) Gegout, P.; Hornain, H.; Thuret, B.; Mortureux, B.; Volant, J.; Regourd, M. Proc. 8th Int. Congr. Chem. Cem. 1986, 197.

(50) Bishop, M.; Barron, A. R. Ind. Eng. Chem. Res. 2006, 45, 7042.

(51) Thomas, N. L.; Birchall, J. D. Cem. Concr. Res. 1983, 13, 830.

(52) Jennings, H. M.; Taleb, H.; Frohnsdorff, G.; Clifton, J. R. Proc. 8th Int. Congr. Chem. Cem. 1986, 239.

(53) Vollet, D. R.; Craievich, A. F. J. Phys. Chem. B 2000, 104, 12143. 393.

(55) Jennings, H. M. J. Am. Ceram. Soc. 1986, 69, 614.

JP809811W 